\title{
Surface chemical properties and pore structure of the activated coke and their effects on the denitrification activity of selective catalytic reduction
}

\author{
Wei Xie ${ }^{1,2,3,4}$ (D) Daming Liang ${ }^{1,3,4} \cdot$ Lanting $\mathrm{Li}^{1,3,4} \cdot$ Sijian $\mathrm{Qu}^{1,2,3,4} \cdot$ \\ Wu Tao ${ }^{1,3,4}$
}

Received: 28 February 2019/Revised: 19 May 2019/Accepted: 13 August 2019/Published online: 13 September 2019

(C) The Author(s) 2019

\begin{abstract}
In order to study the mechanism of selective catalytic reduction of activated coke to remove NO in lowtemperature flue gas and provide some theoretical basis for the development of related technologies. The pore size distribution and BET specific surface area of AC were obtain by data analyzing of $\mathrm{N}_{2}$ adsorption/desorption isotherm at $-196{ }^{\circ} \mathrm{C}$ and carbon matrix and surface chemistry of virgin activated coke samples were characterized by acid-base titration and XPS. The process of selective catalytic reduction of activated coke (AC) samples with $\mathrm{NH}_{3}$ as reducing agent was studied in a fixed bed reactor at $150{ }^{\circ} \mathrm{C}$. The result shows that pore size distribution or BET specific surface of activated cokes have not correlation with denitrification activity for SCR. The NO reduction activities of the activated cokes are apparent to increase with their surface oxygen element content and total amount of acidic sites. Obviously there is good linear relationship between the $\mathrm{NH}_{3}$ adsorption capacity and activity for SCR with linear correlation coefficient 0.943. It has been presented that adsorption of $\mathrm{NH}_{3}$ on acidic functional groups in the edge of large polycyclic aromatic ring of activated coke is key rate controlling step in the SCR heterogeneous catalytic reaction.
\end{abstract}

Keywords Activated coke $\cdot$ SCR $\cdot$ Pore structure $\cdot$ Surface chemical properties $\cdot$ Denitrification

\section{Introduction}

A large amount of Nitrogen oxides $\left(\mathrm{NO}_{x}\right)$ is emitted into the atmosphere from the process of high temperature combustion of fossil fuels, mineral sintering and chemical industry. $\mathrm{NO}_{x}$ can cause the acid precipitation and

\section{Wei Xie}

331xiewei@163.com

1 Beijing Research Institute of Coal Chemistry, China Coal Research Institute, No. 5 Qingniangou Road, Chaoyang District, Beijing 100013, China

2 School of Chemistry and Environment Engineering, China University of Mining and Technology (Beijing), Beijing 100083, China

3 Beijing Key Laboratory of Coal Based Carbon Materials, Beijing 100013, China

4 National Energy Technology and Equipment Laboratory of Coal Utilization and Emission Control, Beijing 100013, China photochemical smog which are considered as serious pollutants. The recently studies have revealed that secondary nitrates aerosols originating from $\mathrm{NO}_{x}$ play important roles in the forming of regional haze and fog pollution (Zhang et al. 2018; Yuan et al. 2015). Although modification in combustion mode technologies reduction of $\mathrm{NO}_{x}$ formation in furnace to some extent (Liu et al. 2018), but the introduction of ultra-low emission standard for atmospheric pollutants in China force the application of flue gas denitrification $\left(\mathrm{DeNO}_{x}\right)$ technologies (Yuan et al. 2017). Currently the most widely employed flue gas $\mathrm{DeNO}_{x}$ technologies is selective catalytic reduction (SCR) which has been successful used in the power plant (Xu et al. 2018).

There is undoubted that catalyst is the key for SCR technologies, the common employed catalysts include noble mental, mental oxide, which have an optimal temperature range of $200-350{ }^{\circ} \mathrm{C}$ (Chen et al. 2018). The exhaust temperature of sintering machine is usually lower than $200{ }^{\circ} \mathrm{C}$ (Zhou et al. 2017) and reducing flue gas 
temperature is beneficial for boiler to improve thermal efficiency (Yu et al. 2018). Consequently, when using these catalysts for denitrification in boiler and sintering flue gas require reheating the flue gas, which means a lot of energy consumption.

The adsorbent and catalytic properties of porous carbonaceous materials are usually relying on their porosity and surface chemistry. In another aspect, the presence of carbon matrix makes porous carbonaceous materials to denitrification at low temperature (120-200 ${ }^{\circ} \mathrm{C}$ ) (Xie et al. 2018a, b). Many high-end carbon materiel products have been prepared from coal, such as graphite or porous grapheme (Xing et al. 2018, 2019). Activated coke as a mature commercial product of porous carbonaceous materials prepared from coal with characteristics of high mechanical strength has been successfully applied in dry $\mathrm{DeNO}_{x}$ process of moving bed (Xie 2017). The catalytic reduction of $\mathrm{NO}$ to $\mathrm{H}_{2} \mathrm{O}$ and $\mathrm{N}_{2}$ with $\mathrm{NH}_{3}$ over activated coke in flue gas is heterogeneous reaction. Mochida et al. first proposed the key reaction of mechanism is $\mathrm{NH}_{3}$ on acidic site on the surface of activated coke (Mochida et al. 1983). However, Gomez et al. revealed that BET surface area has a decisive role in SCR process with samples covering wide rang of surface area of activated carbons (Illan-Gomez et al. 1993). Zhang et al. also proposed that NO filling process in micropore of activated carbon is an important step (Zhang et al. 2008). On the contrary, some research proposed that catalytic activities of activated coke can be significantly improved by chemical modified that introduction of oxygen or nitrogen groups on carbon surface (Abdulrasheed et al. 2018). These conclusions were draw using porous carbonaceous material as catalyst by modification, thus properties of activated coke were not appropriate estimated and introduction of lots of groups by modification may reverse SCR reaction path. Moreover, chemical modification technical will cause production cost rising, so these technologies can not widely used.

The unmodified commercial activated cokes were used for SCR experiments at low temperature. The target of the research is to clarify the influence of pore structure and surface chemistry of the activated cokes and offer same quantitative analysis about the SCR mechanism.

\section{Experimental}

\subsection{Samples}

Five activated coke samples were used in this research (labeled A1-A5) which was prepared from coals with different degrees of metamorphism. The elemental analysis of activated coke samples are listed in Table 1.
Table 1 Elemental analysis of activated coke samples (wt $\%$, daf)

\begin{tabular}{llll}
\hline $\mathrm{C}$ & $\mathrm{H}$ & $\mathrm{O}^{*}$ & $\mathrm{~N}$ \\
\hline 97.12 & 1.05 & 1.37 & 0.46 \\
96.49 & 0.85 & 2.04 & 0.62 \\
96.43 & 1.43 & 1.59 & 0.55 \\
97.15 & 1.34 & 0.79 & 0.72 \\
96.64 & 0.85 & 1.84 & 0.67 \\
\hline
\end{tabular}

daf, dry and ash-free basis; * by difference

The granular of $0.35-0.5 \mathrm{~mm}$ were obtained after milled and sieved from columnar activated coke (i. d. $9 \mathrm{~mm}$ ).

\subsection{Activity measurements for NO reduction}

The NO reduction experiments were operated in the fixedbed experiment bench shown in Fig. 1. The experiment bench consists of a quartz tube (14 mm diameter) as fixed bed reactor, situated in the resistance furnace center jointing gas pipe line and mass flow controllers. The fixedbed reactor exit gases are monitored by mass spectrometer (GAM 200, Germany).

An amount of $1 \mathrm{~g}$ of activated coke was used at each experiment. The reactor was previously heated and sample in $\mathrm{N}_{2}$ atmosphere until $150{ }^{\circ} \mathrm{C}$. Then, the SCR experiment was initiated by substituting $\mathrm{N}_{2}$ by $150 \mathrm{ml} / \mathrm{min}$ with a composition of $1000 \times 10^{-6} \mathrm{NO}, 1100 \times 10^{-6} \mathrm{NH}_{3}$, $10 \% \mathrm{CO}_{2}, 8 \% \mathrm{H}_{2} \mathrm{O}, 6 \% \mathrm{O}_{2}$ and the balance gas, $\mathrm{N}_{2}$.

The NO conversion is used for evaluating the denitrification catalytic activity of the samples, it was calculated as follows:

$\eta=\left(C_{\text {in }, N O}-C_{o u t, N O}\right) \times 100 \% / C_{\text {in }, N O}$

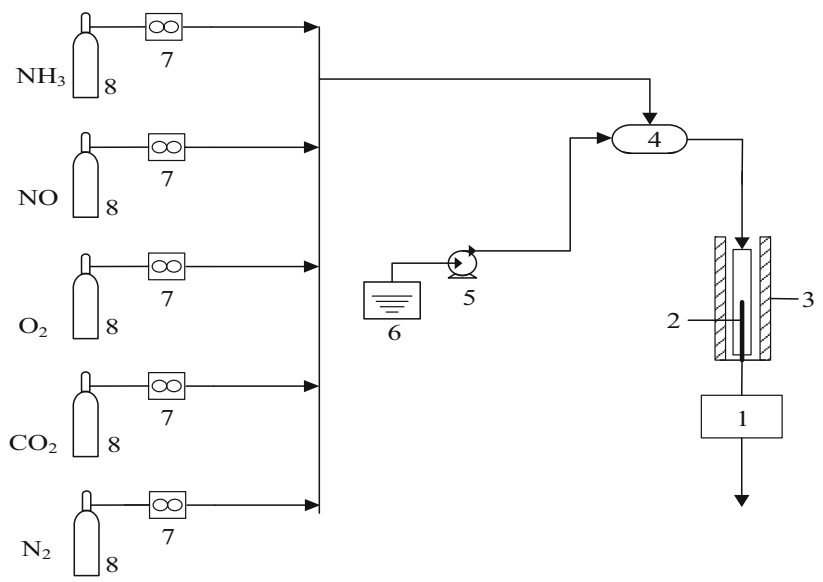

Fig. 1 Experimental system used for SCR. 1. Mass spectrometer; 2. Quartz tube; 3. Resistance furnace; 4. Vaporizer; 5. Gas mixing tank; 6. Water tank; 7. Mass flow meter; 8. High Pressure steel cylinders 
where, $\mathrm{C}_{\mathrm{in}, \mathrm{NO}}$ represent the NO inlet concentrations and $\mathrm{C}_{\mathrm{out}, \mathrm{NO}}$ correspond to its outlet concentrations.

\section{$2.3 \mathrm{NH}_{3}$ adsorption capacity}

The $\mathrm{NH}_{3}$ capacities of activated coke sample are different from each other according their porosity or surface chemical. The $\mathrm{NH}_{3}$ adsorption capacity in per unit mass of activated coke was obtained by integrating of penetration curve versus time. During the experiments, the $1000 \times 10^{-6} \mathrm{NH}_{3}$ and $\mathrm{N}_{2}$ passes through the activated coke layer and $\mathrm{NH}_{3}$ exit concentration gradually increase until steady. Thereby, integrating the penetration curve of $\mathrm{NH}_{3}$ of activated coke samples according to formula (2) can obtain their $\mathrm{NH}_{3}$ adsorption capacity.

$G=F * \frac{M}{W} \int_{0}^{t}\left(1-Y_{\text {out }} / Y_{\text {in }}\right) d t$

where, $F$ is the total gas flow, $w$ is the weight of activated coke, $M$ is the molar mass of $\mathrm{NH}_{3}$, and $Y_{\text {out }}, Y_{\text {in }}$ are the outlet and inlet volume concentration of $\mathrm{NH}_{3}$. The $t$ is the $\mathrm{NH}_{3}$ adsorption time when $\mathrm{NH}_{3}$ outlet concentration reaches steady.

\subsection{Samples characterization}

\subsubsection{Characterization of pore structure}

Pore structure parameters of the virgin activated cokes were determined by $\mathrm{N}_{2}$ adsorption/desorption isotherm at $-196{ }^{\circ} \mathrm{C}$ over the relative pressure range $0.002-0.15 \mathrm{~Pa}$ (Quantchrome Autosorb-1). The Density Functional Theory (DFT) and Brunauer Emmett Teller (BET) equation can be used for calculating pore size distribution (PSD) and specific surface areas, respectively. The mesopore volume can be acquired through total pore volume subtraction of micropore volume which integrating differential pore volume in pore size distribution versus pore diameter. If pores are regard as cylindrical and have no intersection, the average pore diameter can be obtained according to pore volume and surface area.

\subsubsection{Characterization of surface chemical properties}

2.4.2.1 Acid and base re-titration Surface concentrations of acidic and basic sites of activated coke samples can obtain according usual Re-titration (Barton et al. 1997). Weighed amounts $0.5 \mathrm{~g}$ of powder carbon sample of 200 mesh were placed in $25 \mathrm{~mL}$ of about $0.05 \mathrm{~mol} / \mathrm{L} \mathrm{NaOH}$ solution in conical flask, then sealed and $24 \mathrm{~h}$ agitated gently at home temperature for chemical equilibrate. The liquid was then separated by filter paper. Measuring of
$10 \mathrm{ml} \mathrm{NaOH}$ supernatant was depleted with a $0.05 \mathrm{~mol} / \mathrm{L}$ $\mathrm{HCl}$ solution until $\mathrm{pH}$ value of the titrant solution was up to 7. The concentration of surface acidic sites was calculated by:

$C_{H^{+}}=\frac{n \cdot m\left(\mathrm{OH}^{-}\right)-\Delta n \cdot m\left(\mathrm{H}^{+}\right)}{W}$

where, $n$ and $m\left(\mathrm{OH}^{-}\right)$are the volume and concentration of the $\mathrm{NaOH}$ solution respectively; $\Delta n$ is the titration volume of $\mathrm{HCL}$ solution; $m\left(\mathrm{H}^{+}\right)$is the concentration of $\mathrm{HCl}$; and $w$ is the weight of activated coke samples. The similar operation was used to determine the concentrations of basic sites with $\mathrm{HCl}$ as impregnating solution and using $\mathrm{NaOH}$ as titration solution.

2.4.2.2 X-ray photoelectron spectroscopy X-ray photoelectron spectroscopy (XPS) can be used to characterize the surface chemical properties of activated cokes. The XPS model used in the experiment is Thermo ESCALAB 250 with $\mathrm{Al} \mathrm{K} \alpha$ radiation $(\mathrm{h} v=1486.6 \mathrm{eV})$. The $\mathrm{C} 1 \mathrm{~s}$ peak $\left(\mathrm{E}_{\mathrm{b}}(\mathrm{C} 1 \mathrm{~s})=284.6 \mathrm{eV}\right)$ was taken as an internal standard. Data processing was executed using software of XPSPeak 4.1 with least square fitting algorithm and a Shirley baseline. The $\mathrm{C} 1 \mathrm{~s}$ high resolution peaks were fitted using Lorentzian-Gaussian equation.

\section{Result and discussion}

\subsection{Physical characteristics of the activated cokes}

The BET specific surface areas of the activated cokes are given in Table 2. Pore structures characteristics confirm a micro porous character of all samples, with the pore structure in the pore width of $0.35-2 \mathrm{~nm}$ constituting the most specific surface areas. The microporous BET specific surface area and total BET specific surface area of A1 reached 459.3 and $471.8 \mathrm{~m}^{2} / \mathrm{g}$, respectively, which was the highest among all samples.

Figure 2 shows the pore size distributions (PSD) of activated coke samples. In Fig. 2, all samples have almost

Table 2 The pore structure of the activated cokes

\begin{tabular}{lll}
\hline Sample & \multicolumn{2}{l}{ BET surface area $\left(\mathrm{m}^{2} / \mathrm{g}\right)$} \\
\cline { 2 - 3 } & Total pore & Micro pore $(<2 \mathrm{~nm})$ \\
\hline A1 & 471.8 & 459.3 \\
A2 & 355.6 & 346.2 \\
A3 & 389.6 & 386.3 \\
A4 & 220.6 & 210.8 \\
A5 & 259.9 & 245.6 \\
\hline
\end{tabular}




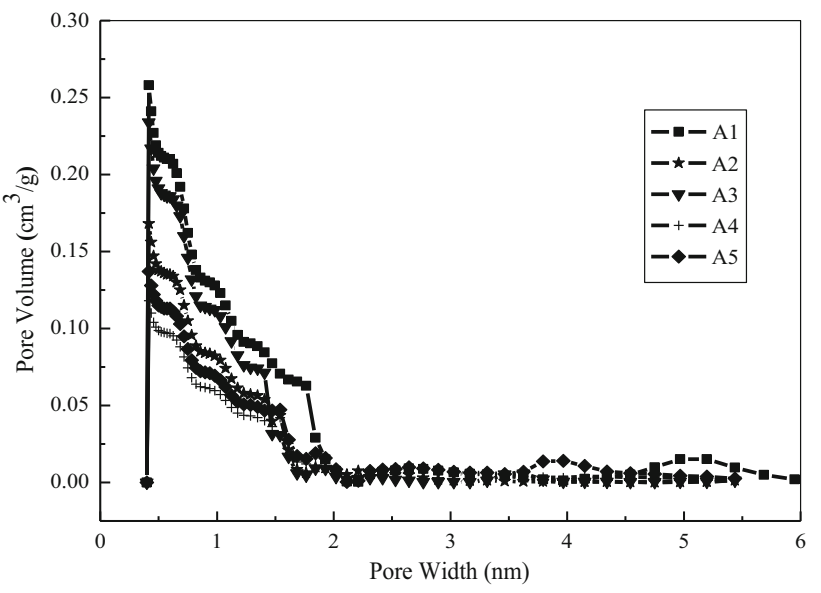

Fig. 2 Pore size distribution of the activate coke samples

same range of pore size distribution, but the region and intensity of distribution for those samples are different. The distribution intensity of A4 is low for pore volume at all of pore width range, which shows that pore structure of A4 is not well developed. A1 has a high intensity of micro pores compared with the other samples, which shows that A1 has a high micro pore volume and the BET specific surface area parameters can be mutually verified.

\subsection{Surface chemical properties}

The results of concentration of surface acidic and basic sites in the samples determined by acid-base Re-titration method is shown in Table 3.

The concentration of surface basic sites in the samples was significantly lower than that of surface acidic sites. The concentration both basic and acidic sites in A4 and A5 were more than those in $\mathrm{A} 1$ and $\mathrm{A} 2$. Considering the surface areas for A4 and A5 were $220.6 \mathrm{~m}^{2} / \mathrm{g}$ and $259.9 \mathrm{~m}^{2} / \mathrm{g}$ respectively, the intensity of surface and basic in A4 and A5 were higher than others samples.

The XPS can detect the carbon surface to a maximum depth of $10 \mathrm{~nm}$ (Sousa et al. 2013). Thus these results indicate not only oxygen and nitrogen functional groups but also structure of carbon layer. The elemental contents of the activated coke surface analyzed by XPS survey spectra are showed in Table 4. The activated coke surface oxygen element taken up during activation process whereas

Table 3 Concentration of surface acidic and basic sites of the activated cokes

\begin{tabular}{llllll}
\hline Concentration $(\mathrm{mmol} / \mathrm{g})$ & $\mathrm{A} 1$ & $\mathrm{~A} 2$ & $\mathrm{~A} 3$ & $\mathrm{~A} 4$ & $\mathrm{~A} 5$ \\
\hline Concentration of acidic sites & 1.089 & 1.057 & 1.151 & 1.258 & 1.342 \\
Concentration of basic sites & 0.410 & 0.439 & 0.728 & 1.149 & 1.001 \\
\hline
\end{tabular}

Table 4 Elemental contents of the samples surface measured by XPS (\%)

\begin{tabular}{llll}
\hline Sample & N & O & C \\
\hline A1 & 0.41 & 10.32 & 89.24 \\
A2 & 0.62 & 10.07 & 89.28 \\
A3 & 0.66 & 13.71 & 85.62 \\
A4 & 0.78 & 14.02 & 85.17 \\
A5 & 0.67 & 14.34 & 84.96 \\
\hline
\end{tabular}

hetero atoms nitrogen may originate raw (László et al. 2001). The graphitic carbon layers are easily attacked by oxygen or activating agent at their periphery or at defect, hence the surface oxygen groups are bound to the edges of the carbon layers (Boehm 1994).

The $\mathrm{C} 1 \mathrm{~s}$ deconvolution peaks obtained from XPS spectrums could be ascribed to the carbon matrix and/or bonded different functional groups. According to the literature (Ju et al. 2008), mainly 5 peaks are usually have been fitted. Figures 3 show the high resolution deconvolution of $\mathrm{C} 1 \mathrm{~s}$ of $\mathrm{A} 1$ as an example. The optimization deconvolution was achieved for C1s spectrum: graphitic carbon layer $\mathrm{C} 1 \mathrm{~s} 1(\mathrm{BE}=284.0-285.1 \mathrm{eV}), \mathrm{C}=\mathrm{N}$ groups or ether, phenolic, alcohol $\mathrm{C} 1 \mathrm{~s} 2(\mathrm{BE}=285.3-286.3 \mathrm{eV})$, quinone or carbonyl groups $\mathrm{C} 1 \mathrm{~s} 3(\mathrm{BE}=286.8-288.1 \mathrm{eV})$, ester or carboxyl groups C1s4 $(\mathrm{BE}=288.5-290.0 \mathrm{eV})$, and $\pi-\pi *$ transitions in large polycyclic aromatic ring systems C1s5 (BE = 290.2-291.1 eV).

The results of five different forms of peaks calculated by integral for area are shown in Table 5.

The material basis of carbon matrix mainly constitutes large polyaromatic ring structure. The $\pi-\pi^{*}$ transitions in carbon matrix of activated coke surface can bind protons and thus reflects basic property (Boehm 1994). The

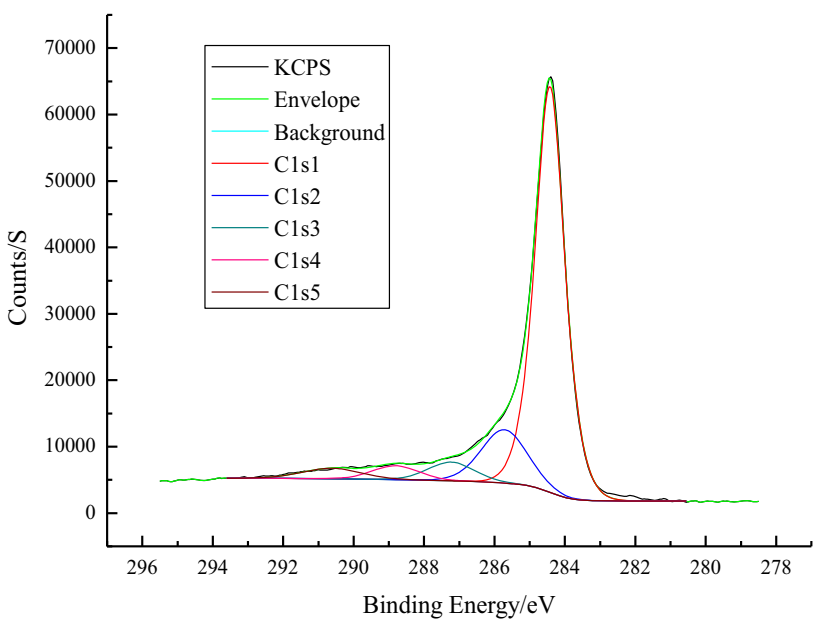

Fig. 3 High resolution of $\mathrm{C} 1 \mathrm{~s}$ spectrum of the A1 
Table 5 Distribution of the five forms of the samples

\begin{tabular}{lrrrrr}
\hline Content $(\%)$ & A1 & \multicolumn{1}{l}{ A2 } & \multicolumn{1}{l}{ A3 } & \multicolumn{1}{l}{ A4 } & \multicolumn{1}{c}{ A5 } \\
\hline C1s1 & 65.56 & 63.41 & 57.55 & 57.74 & 57.61 \\
C1s2 & 12.74 & 13.47 & 15.05 & 14.35 & 14.59 \\
C1s3 & 4.48 & 5.21 & 5.87 & 5.60 & 5.41 \\
C1s4 & 3.36 & 3.81 & 3.85 & 3.73 & 3.71 \\
C1s5 & 3.16 & 3.34 & 3.26 & 3.71 & 3.63 \\
\hline
\end{tabular}

concentration of basic sites order of $\mathrm{A} 4>\mathrm{A} 5>\mathrm{A} 3>$ A2 $>$ A1 is different from $\pi-\pi^{*}$ content order of A4 $>$ $\mathrm{A} 5>\mathrm{A} 2>\mathrm{A} 3>\mathrm{A} 1$. It may be that the presence of basic oxygen-containing or nitrogen-containing functional groups on the surface affects the total amount of acid and base on the surface (Grzyb et al. 2009).

Acidity property of the surface of the activated coke comes from the fact that acidic functional groups that can give protons to other substances. The richer the surface oxygen element content, the dispersion is the more acidic (Xie et al. 2014). Carbon with low oxygen element content shows anion exchange behavior and basic surface property (Boehm 1994). The oxygen element content of the activated coke surface probed by XPS follows a same order to that concentration of acidic sites measured by Re-titration. Equivalently to Re-titration results, the highest and lowest of oxygen element content are A5 and A2, respectively. The concentration of acidic sites of the activated coke samples have an rank of A5 $>$ A4 $>$ A3 $>$ A1 $>$ A2 .

\subsection{NO reduction activities of the activated cokes}

The variations of NO conversion for the reaction of SCR by different activated cokes at $150{ }^{\circ} \mathrm{C}$ were shown in Fig. 4. These curves indicate a pattern in which NO

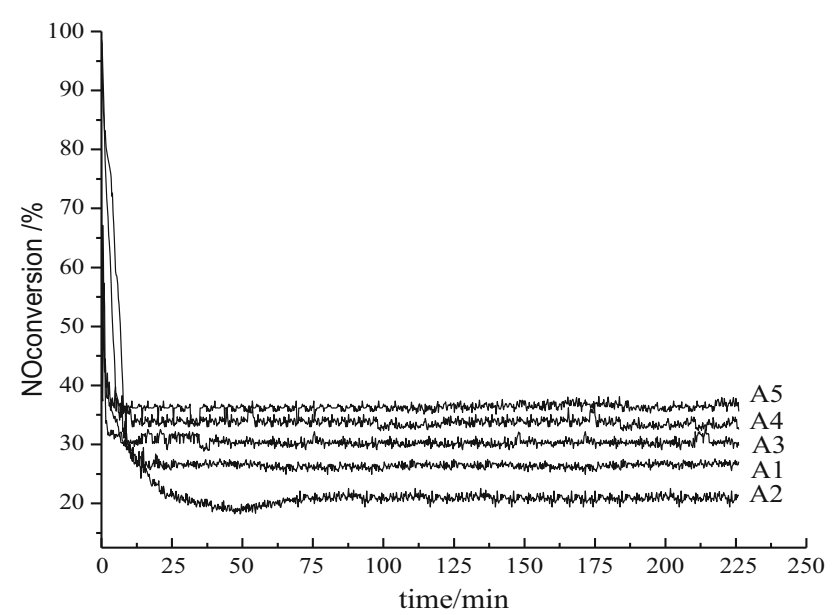

Fig. 4 Reaction profiles of NO conversion over the activated cokes conversion decreases remarkably in the initial period of the denitrification and then remain steady-state lasting more than $200 \mathrm{~min}$. Some studies have reported that NO can be physical adsorbed directly by carbon materials at low temperature (Zhu et al. 2000; Teng et al. 2001). It is deduced that NO physical adsorbed as well as reduction of SCR lead to higher denitrification efficiency, during the initial stage of the NO conversion. Hence, it is concluded that stabilized NO conversion ascribed activated coke reach saturation for NO physical adsorption and NO reduction be totally controlled by SCR reaction.

The calculated results of stabilized NO conversion reflected the SCR activities of samples are summarized in Table 6.

It is well known that micropore and specific area of carbonaceous materials is very useful for gas physical adsorption. Previous investigation showed that the optimum adsorption pore size of activated carbon is $1.7-3$ times to that of adsorbate (Xie et al. 2005). However, it has been found that the weak correlation between the most probable apertures with the molecular diameter for $0.317 \mathrm{~nm}$ of $\mathrm{NO}$ or $0.38 \mathrm{~nm}$ of $\mathrm{NH}_{3}$. In other hand, Zhang et al. proposed that $\mathrm{NO}$ filling process in micropore of activated carbon is an important step for $\mathrm{NO}$ oxidation to $\mathrm{NO}_{2}$ (Zhang et al. 2008). Koebel purposed that the process of catalytic oxidation of $\mathrm{NO}$ to $\mathrm{NO}_{2}$ is an important path of SCR mechanism and equimolar amount of $\mathrm{NO}$ and $\mathrm{NO}_{2}$ can facilitate SCR reaction (Koebel et al. 2002). However, there are no correlations between stabilized NO conversions with the data of pore structure or BET surface area. Although, A1 and A2 have high micropore volume and thus high contribution to BET surface area, they do not exhibit high conversion of NO reduction, thus the correlation cannot be made.

It is the difficult to correlate stabilized NO conversions of the samples with any carbon functional groups fitted high resolution deconvolution of $\mathrm{C} 1 \mathrm{~s}$. The nitrogen functional groups are mostly basic, such as pyridine and pyrrole (Xie et al. 2018a, b), and its content is significantly lower than that of oxygen functional groups on the unmodified activated coke surface. Nevertheless, the stabilized NO conversion could be correlated with total content of surface oxygen element analyzed XPS survey spectra or concentration of acidic sites by re-titration. In Figs. 5 and 6 the stabilized NO conversion are plotted against the oxygen

Table 6 The stabilized NO conversions of the activated coke samples $(\%)$

\begin{tabular}{lllll}
\hline A1 & A2 & A3 & A4 & A5 \\
\hline 26.42 & 20.69 & 30.32 & 33.72 & 36.34 \\
\hline
\end{tabular}




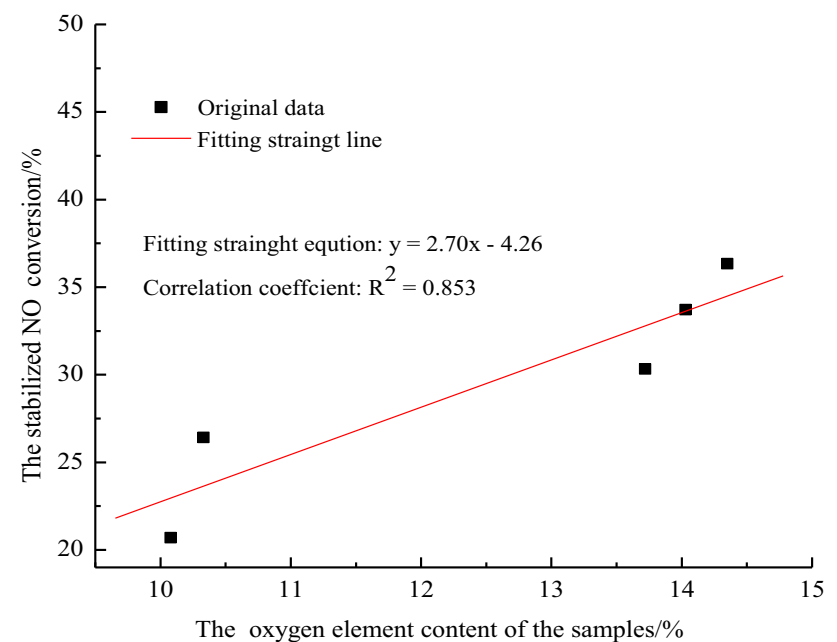

Fig. 5 Relationship between oxygen element content and stabilized NO conversion

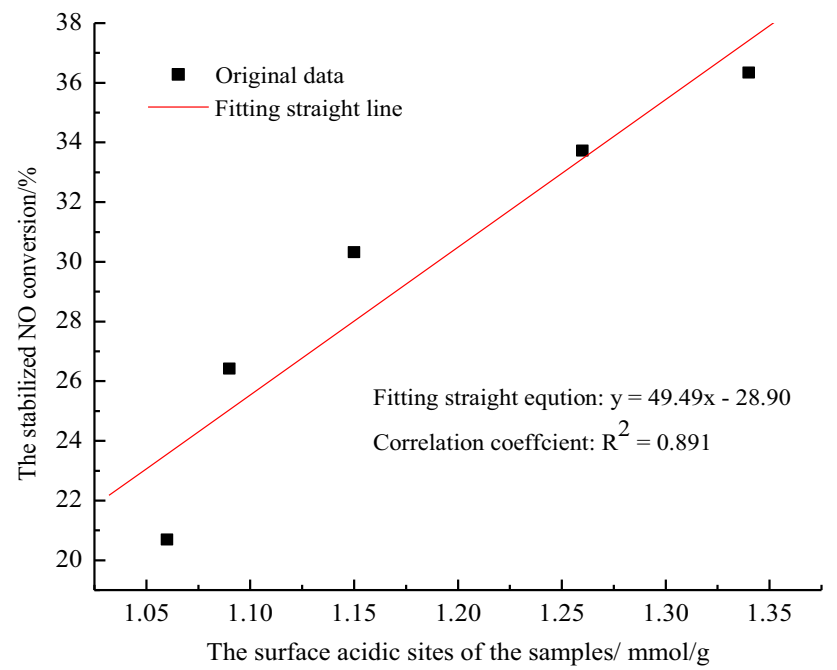

Fig. 6 Relationship between acidic sites and stabilized NO conversion

element content and acidic sites respectively, and the fitting straight equation was obtained by the least square method fitting of the original data. The linear correlation coefficient $\left(R^{2}=0.891\right)$ between acid sites and stabilized NO conversion rates was significantly higher than that $\left(R^{2}=0.853\right)$ between oxygen element and NO conversion.

The present work has demonstrated that the stabilized NO conversion increase with the surface acidic properties of activated coke. Previous studied ascribed the acidic properties of carbonaceous materials to its surface oxygen groups. Boehm summarized the carboxyl; carboxylic anhydride or lactons that in the edge graphene layer is acidic oxygen functional groups (Boehm 1994). The basic properties of carbonaceous materials originate from the $\pi$ electrons within the graphite planes, but is has been shown that the surface presence of oxygen structures is also sufficiently basic. Boehm considered that the basic oxygen structures to chromene-like, ether-type or xanthene-type is very difficult to detect (Boehm 1994). The surface properties of the activated cokes by re-titration showed relatively precise surface acidity than oxygen element content by XPS and they had strong affinity for basic $\mathrm{NH}_{3}$ molecules through comparing correlation coefficient.

Two SCR mechanisms proposed of metal oxides are used to describe the SCR process of activated coke (Zhu et al. 2000): (1) adsorbed $\mathrm{NH}_{3}$ with gaseous phase $\mathrm{NO}$ to form an active intermediate species which is then decomposed into $\mathrm{H}_{2} \mathrm{O}$ and $\mathrm{N}_{2}$; (2) the adsorbed state $\mathrm{NO}$ at sites in the ortho position adsorbed $\mathrm{NH}_{3}$, subsequently reaction between them to form the final products. Although, there is a common agreement for SCR mechanism that $\mathrm{NH}_{3}$ adsorption on activated carbon/coke surface is an important step whereas it is hard to prove the SCR activity for NO removal with in the presence of $\mathrm{NH}_{3}$. Figure 7 presents the stabilized $\mathrm{NO}$ conversion versus $\mathrm{NH}_{3}$ adsorption capacity.

A good correlation between stabilized NO conversion and $\mathrm{NH}_{3}$ adsorption capacity of the activated cokes has been found. The fitting straight equation was also acquired with least square method based on the original data. There is evident that the linear correlation coefficient $\left(R^{2}=0.943\right)$ of $\mathrm{NH}_{3}$ adsorption capacity and stabilized $\mathrm{NO}$ conversion is higher than those linear correlation coefficient related to surface properties. It is deduced that $\mathrm{NH}_{3}$ adsorption capacity directly reflects the binding capacity of active cokes to $\mathrm{NH}_{3}$, which should be a combination of surface chemical properties, pore structure or other influencing factors. It was thus suggested that the reduction of $\mathrm{NO}$ with $\mathrm{NH}_{3}$ over activated coke be controlled by the adsorption of $\mathrm{NH}_{3}$ rather than step between $\mathrm{NO}$ with

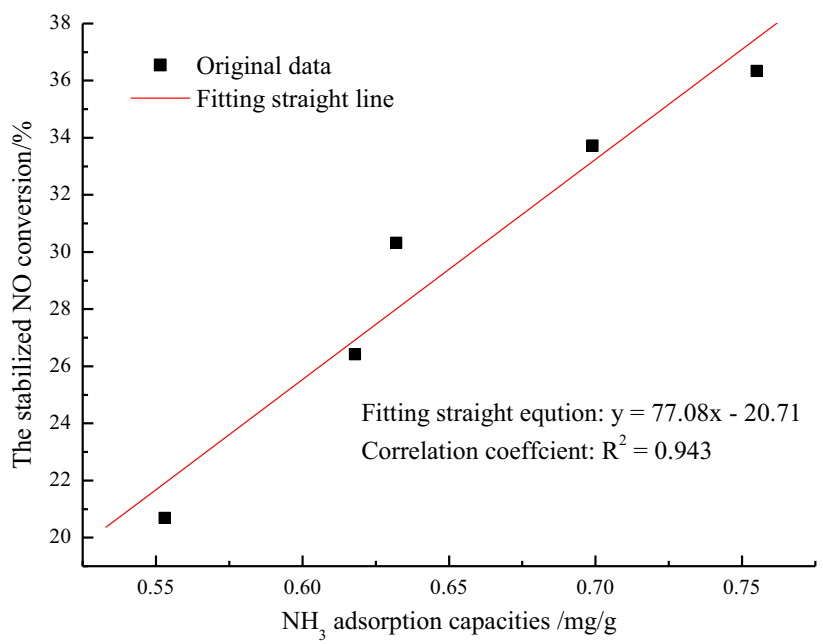

Fig. 7 Relationship between stabilized $\mathrm{NO}$ conversions and $\mathrm{NH}_{3}$ adsorption capacities by the samples 

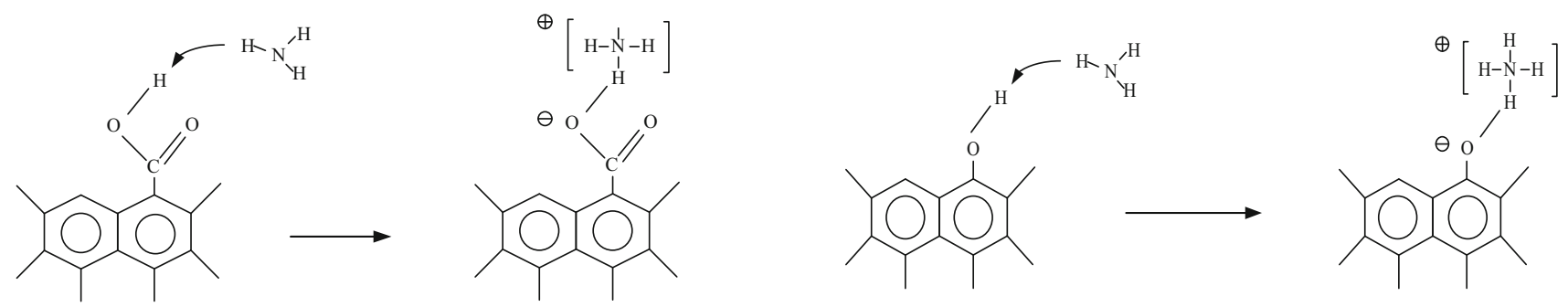

Fig. 8 Reaction step for the formation of surface $\left[\mathrm{NH}_{4}\right]^{+}$complexes during SCR

adsorbed $\mathrm{NH}_{3}$. The surface chemical properties of activated coke is undoubtedly the most important factor for process of $\mathrm{NH}_{3}$ adsorption. Therefore, the key step of SCR is the reaction of $\mathrm{NH}_{3}$ with the acidic sites, such as carboxylic and phenolic groups, as shown in Fig. 8.

It is acknowledge that carboxyl and phenolic hydroxyl on the activated coke surface could react with basic $\mathrm{NH}_{3}$. The carbon matrix of activated coke is compose large polycyclic aromatic ring and branched chain-like carbon structure (Zhu et al. 2017). The carboxyl and phenolic hydroxyl are usually in the edge of large polycyclic aromatic ring (Boehm 1994). The reaction step involve the interaction of $\mathrm{NH}_{3}$ with proton part of carboxyl groups to form $\mathrm{CO}^{-}\left(\mathrm{NH}_{4}{ }^{+}\right)$and phenolic groups to form $\mathrm{O}^{-}\left(\mathrm{NH}_{4}{ }^{+}\right)$. The formation of $\mathrm{CO}^{-}\left(\mathrm{NH}_{4}{ }^{+}\right)$and $\mathrm{O}^{-}\left(\mathrm{NH}_{4}{ }^{+}\right)$instead of carboxyl and phenolic groups, are very critical steps for NO reduction on activated coke surface.

As shown above, pore structure properties presented by pore size distribution and BET surface hardly affects the catalytic activity of the activated cokes for SCR. $\mathrm{NH}_{3}$ and NO kinetic diameter are $0.26 \mathrm{~nm}$ and $0.317 \mathrm{~nm}$ respectively (Poling et al. 2001), they all in the micropore diameter range. In this sense, it can infer that physical properties mainly exert the accessibility of reactants towards the active centers. A good correlation between stabilized $\mathrm{NO}$ conversion and $\mathrm{NH}_{3}$ adsorption capacity of the activated cokes indicates that acidic sites are active centers for SCR catalytic reaction. The adsorption of $\mathrm{NH}_{3}$ on acidic functional groups of the activated coke is key rate controlling step in the SCR heterogeneous catalytic reaction.

\section{Conclusion}

At present study, pore structure and surface chemical properties of activated coke over adequate samples having a variety were analyzed and denitrification activities of samples for SCR were measured in fixed bed at $150{ }^{\circ} \mathrm{C}$.

(1) It is difficult to correlate the denitrification activity for SCR of the activated cokes with their pore structure characteristic. The NO reduction activities of the activated cokes are apparent to increase with their surface oxygen element content and total amount of acidic sites.

(2) Obviously there is good linear relationship between the $\mathrm{NH}_{3}$ adsorption capacity and activity for SCR with linear correlation coefficient 0.943 .

(3) It has been presented that adsorption of $\mathrm{NH}_{3}$ on acidic functional groups in the edge of large polycyclic aromatic ring of activated coke is key rate controlling step in the SCR heterogeneous catalytic reaction.

Acknowledgements The authors are grateful to the National Key Research and Development Program of China (NO. 2016YFC0204100)

Open Access This article is distributed under the terms of the Creative Commons Attribution 4.0 International License (http://crea tivecommons.org/licenses/by/4.0/), which permits unrestricted use, distribution, and reproduction in any medium, provided you give appropriate credit to the original author(s) and the source, provide a link to the Creative Commons license, and indicate if changes were made.

\section{References}

Abdulrasheed AA, Jalil AA, Triwahyono S, Zaini MAA, Gambo Y, Ibrahim M (2018) Surface modification of activated carbon for adsorption of $\mathrm{SO}_{2}$ and $\mathrm{NO}_{\mathrm{x}}$ : a review of existing and emerging technologies. Renew Sustain Energy Rev 94:1067-1085

Barton SS, Evans MJB, Halliop E, MacDonald JAF (1997) Acidic and basic sites on the surface of porous carbon. Carbon 35:1361-1366

Boehm HP (1994) Some aspects of the surface chemistry of carbon blacks and other carbons. Carbon 32:759-769

Chen C, Cao Y, Liu S, Chen JM, Jia WB (2018) Review on the latest developments in modified vanadium-titanium-based SCR catalysts. Chin J Catal 39:1347-1365

Grzyb B, Albiniak A, Broniek E, Furdin G, Marêché JF, Bégin D (2009) $\mathrm{SO}_{2}$ adsorptive properties of activated carbons prepared from polyacrylonitrile and its blends with coal-tar pitch. Microporous Mesoporous Mater 118:163-168

Illan-Gomez MJ, Linares-Solano A, Salinas-Martinez De Lecea C, Calo JM (1993) Nitrogen oxide (NO) reduction by activated carbons. 1. The role of carbon porosity and surface area. Energy Fuels 7:146-154 
Ju S, Li C, Miao M, Yang Z (2008) Surface characterization and SO2 removal activity of activated semi-coke with heat treatment. New Carbon Mater 23:37-43

Koebel M, Madia G, Elsener M (2002) Selective catalytic reduction of $\mathrm{NO}$ and $\mathrm{NO}_{2}$ at low temperatures. Catal Today 73:239-247

László K, Tombácz E, Josepovits K (2001) Effect of activation on the surface chemistry of carbons from polymer precursors. Carbon 39:1217-1228

Liu X, Tan H, Wang Y, Yang FX, Mikulčić H, Vujanović M, Duić N (2018) Low $\mathrm{NO}_{\mathrm{x}}$ combustion and SCR flow field optimization in a low volatile coal fired boiler. J Environ Manag 220:30-35

Mochida I, Ogaki M, Fujitsu H, Komatsubara Y, Ida S (1983) Catalytic activity of coke activated with sulphuric acid for the reduction of nitric oxide. Fuel 62:867-868

Poling BE, Prasusniltz JM, Connell JPO (2001) The properties of gases and liquids. MacGraw Hill, New York

Sousa JPS, Pereira MFR, Figueiredo JL (2013) Modified activated carbon as catalyst for NO oxidation. Fuel Process Technol 106:727-733

Teng H, Tu Y, Lai Y, Lin CC (2001) Reduction of $\mathrm{NO}$ with $\mathrm{NH}_{3}$ over carbon catalysts: the effects of treating carbon with $\mathrm{H}_{2} \mathrm{SO}_{4}$ and $\mathrm{HNO}_{3}$. Carbon 39:575-582

Xie W (2017) Application statue and development trend if coal-based activated carbon in China. Coal Sci Technol 45:16-23

Xie Q, Zhang XL, Li LT, Jin L (2005) Porosity adjustment of activated carbon: theory, approaches and practice. New Carbon Mater 20:183-190

Xie W, Sun ZC, Xiong YW, Li LT, Wu T, Liang DM (2014) Effects of surface chemical properties of activated coke on selective catalytic reduction of $\mathrm{NO}$ with $\mathrm{NH}_{3}$ over commercial coal-based activated coke. Int J Mining Sci Technol 24(4):471-475

Xie W, Qu SJ, Wang P, Liang DM, Li XL, Wu Q (2018a) Low temperature flue gas denitrification performance of carbon materials prepared by blending coal method. Clean Coal Technol 24:102-107

Xie W, Qu SJ, Wang P, Li LT, Yu QH (2018b) Study on optimizing denitrification of activated coke loading $\mathrm{NH}_{3}$ under moving bed process. Coal Sci Technol 46:209-213
Xing BL, Zhang CT, Cao YJ, Huang GX, Liu QR, Zhang CX, Chen ZF, Yi GY, Chen LJ, Yu JL (2018) Preparation of synthetic graphite from bituminous coal as anode materials for high performance lithium-ion batteries. Fuel Process Technol 172:162-171

Xing BL, Zeng HH, Huang GX, Zhang CX, Yuan RF, Cao YJ, Chen $\mathrm{ZF}$, Yu JL (2019) Porous graphene prepared from anthracite as high performance anode materials for lithium-ion battery applications. J Alloy Compd 779:202-211

Xu J, Chen G, Guo F et al (2018) Development of wide-temperature vanadium-based catalysts for selective catalytic reducing of NOx with ammonia: review. Chem Eng J 353:507-518

Yu QH, Xu ZG, Ji RS, Xie JQ (2018) Mechanism analyzing and industrialization experiment on technology of ash calcium circulating flue gas desulfurization. China Coal 44:147-152

Yuan Q, Li W, Zhou S, Yang LX, Chi JW, Sui X, Wang WX (2015) Integrated evaluation of aerosols during haze-fog episodes at one regional background site in North China Plain. Atmos Res 156:102-110

Yuan X, Zhang M, Wang Q, Li H, Liang X (2017) Evolution analysis of environmental standards: Effectiveness on air pollutant emissions reduction. J Clean Prod 149:511-520

Zhang WJ, Rabiei S, Bagreev A, Zhuang MS, Rasouli F (2008) Study of NO adsorption on activated carbons. Appl Catal B 83:63-71

Zhang R, Sun X, Shi A, Huang YH, Yan J, Nie T, Yan X, Li X (2018) Secondary inorganic aerosols formation during haze episodes at an urban site in Beijing, China. Atmos Environ 177:275-282

Zhou H, Chen J, Zhou M, Cen KF (2017) Experimental investigation on the mixing performance of heating gas into the low temperature sintering flue gas selective catalyst reaction facilities. Appl Therm Eng 115:378-392

Zhu ZP, Liu ZY, Liu SY, Niu HX (2000) Adsorption and reduction of NO over activated coke at low temperature. Fuel 79:651-658

Zhu YW, Li HY, Liu DD, Gao JH, Liu HQ (2017) Development mechanism of pore structures based on burn-off properties of carbon structures during activation process. J China Coal Soc 42:3292-3299 